P07

\section{Elegant and Mysterious Structures of Minerals}

\author{
Dmitry Yu Pushcharovsky \\ Geology Department, Moscow State University, 119992 Moscow, Russia; \\ E-mail:dmitp@geol.msu.ru
}

\section{Keywords: mineralogical crystallography, mineral structures, arsenates}

Some of exciting recent developments in the field of mineralogical crystallography are considered. The crystal chemical phenomena (e.g. ionic ordering, polyhedral stacking variations, microtwinning etc.) which accompany the formation of real structures, are discussed on the basis of structural studies of a large group of minerals. The new approaches used for their investigation allowed extending the scientific ideas connected with: status of new and questionable minerals, structural classification of minerals, forms of concentration of chemical elements in the Earth's crust, further development of modular theory and other problems of modern structural mineralogy. The advantage of using of synchrotron radiation opens the gate to a new branch of microgeochemistry (about $20 \%$ of known minerals lack a structure determination, mainly because crystals are too small or imperfect for laboratory X-ray sources). As an example the structures of three arsenates are considered. Two of them are $\mathrm{Cu}$-arsenates, namely zdenekite, $\mathrm{NaPbCu}_{5}\left(\mathrm{AsO}_{4}\right)_{4} \mathrm{Cl}\left(5 \mathrm{H}_{2} \mathrm{O}\right.$ and mahnertite, $(\mathrm{Na}, \mathrm{Ca}) \mathrm{Cu}_{3}\left[\mathrm{AsO}_{4}\right]_{2}\left(\mathrm{Cl}\left(5 \mathrm{H}_{2} \mathrm{O}\right.\right.$, contain the new type of mixed polyhedral sheets which are characterized by the different mode of their stacking. The specific feature of these layers are the clusters, formed by four $\mathrm{Cu}\left({ }_{5}\right.$ pyramids $\left(\phi=\mathrm{O}, \mathrm{Cl}, \mathrm{H}_{2} \mathrm{O}\right)$ with shared edges.

Tillmannsite, $\left(\mathrm{Ag}_{3} \mathrm{Hg}\right)(\mathrm{V}, \mathrm{As}) \mathrm{O}_{4}$, was found in the old copper mines of Roua (Alpes-Maritimes, France) and its structure is characterised by the presence of two types of tetrahedra: metallic clusters formed by $\mathrm{Ag}$ and $\mathrm{Hg}$ atoms and $\mathrm{As}, \mathrm{V}$-tetrahedra. Similar metallic clusters were revealed in the crystal structures of synthetic $\mathrm{Ag}, \mathrm{Hg}$-vanadates and arsenate [1]. The chemical composition of biraite- $(\mathrm{Ce}), \mathrm{Ce}_{2} \mathrm{Fe}^{2+}\left(\mathrm{CO}_{3}\right)\left(\mathrm{Si}_{2} \mathrm{O}_{7}\right)$, which is a new mineral from Siberia with a new structural arrangement, was established as a result of its XRD study, IR-spectroscopy and thermal analysis. The crystal structures of armstrongite, $\mathrm{CaZr}\left[\mathrm{Si}_{6} \mathrm{O}_{15}\right] \times 3 \mathrm{H}_{2} \mathrm{O}$, which was discovered in a granite pegmatite and alkaline granites of Mongolia, and of two forms of holtite were refined using the Rietveld method. As a result the chemical composition of these minerals was determined. Apparently the new discoveries of minerals will be in the focus of new XRD studies with the use of new methods in the nearest future and will open the new era in physics and chemistry of minerals.

[1] Weil, M., Tillmanns, E., Pushcharovsky, D.Yu.(2005): Inorg. Chem., 44, 1443-1451.
P08

\section{Halogen-mediated supramolecular chemistry in the solid state}

Lee Brammer, Guillermo Mínguez Espallargas and Fiorenzo Zordan

Department of Chemistry, University of Sheffield, Brook Hill, Sheffield S37HF,UK.E-mail:lee.brammer@sheffield.ac.uk

\section{Keywords: crystal engineering, hydrogen bonds, solid-state reactions}

Halogens have been demonstrated to be highly effective and directional hydrogen bond acceptors when bound to metal centres (M-X), wherein they serve as Lewis bases in interactions with typical hydrogen bond donors (N-H, O-H, etc.).[1-3] By contrast, organic halides $(\mathrm{C}-\mathrm{X})$ are extremely poor hydrogen bond acceptors, [1] but known to participate in so-called halogen bonds, wherein the $\mathrm{C}-\mathrm{X}$ group plays a Lewis acidic role, viz. $\mathrm{N} \cdots \mathrm{X}-\mathrm{C}, \mathrm{O} \cdots \mathrm{X}-\mathrm{C} .[4]$

Recently we have developed a new class of halogen bonds by combining these two contrasting but complementary capabilities of halogens (M-X '- X'-C) and shown this to be an effective interaction that may be applied as a supramolecular synthon in the construction of supramolecular assemblies in crystals.[5-7] Some examples using both neutral and charge-assisted interactions of this type will be discussed and a comparison of the behaviour of different halogens $(\mathrm{X})$ will be explored.

Complementary experimental and theoretical studies demonstrate that $\mathrm{M}-\mathrm{X} \cdots \mathrm{X}^{\prime}-\mathrm{C}$ are predominantly electrostatic in nature rather than dominated by the charge transfer as might have been anticipated.[6,7] These studies suggest an electronic description of halogen bonds ranging from weakest to strongest that parallel the description of hydrogen bonds.

Finally, this class of compounds undergoes a number of interesting solid state reactions, which will also be discussed.

[1] L. Brammer, E. A. Bruton and P. Sherwood, Cryst. Growth Des. 2001, 1, 277.

[2] L. Brammer, J. K. Swearingen and P. Sherwood, Proc. Nat. Acad. Sci., USA 2002, 99, 4956; J. C. Mareque Rivas and L. Brammer, Inorg. Chem. 1998, 37, 4756.

[3] A. Angeloni and A. G. Orpen, Chem. Commun. 2001, 343; B. Dolling, A. L. Gillon, A. G. Orpen, J. Starbuck and Xi-Meng Wang, Chem. Commun. 2001, 567.

[4] P. Metrangolo, H. Neukirch, T. Pilati, G. Resnati, Acc. Chem. Res. 2005, 38, 386.

[5] L. Brammer, G. Mínguez Espallargas and H. Adams, CrystEngComm 2003, 5, 343.

[6] F. Zordan, L. Brammer and P. Sherwood, J. Am. Chem. Soc. 2005, $127,5$.

[7] G. Mínguez Espallargas, L. Brammer and P. Sherwood, Angew. Chem., Int. Ed. 2006, 45, 435. 